RU Специфика лексикографирования немецких негативно-оценочных лексических единиц

\author{
Николаева Н. Т., Турецкова И. В.
}

Аннотация. Цель исследования заключается в выявлении лингвистического статуса немецких пейоративных лексем, описывающих человека, на базе лексикографических справочников. В статье исследуются немецкие лексические единицы, имеющие высокий экспрессивный заряд и включающие весь диапазон негативно-оценочных, уничижительных, депрециативных значений. Научная новизна заключается в разработке принципов выбора номинаций с пейоративным значением из общего лексического фонда языка и определении особенностей их маркирования в немецких и немецкорусских лексикографических источниках. В результате количественного, стилистического и этимологического анализа получено 1492 номинации с семантикой пейоративности, выделены отличительные особенности пейоративов, охарактеризованы пейоративные пометы и их вариации в различных словарях и справочниках.

\title{
EN Specificity of Lexicographic Work on German Negative Evaluative Lexical Units
}

\author{
Nikolaeva N. T., Turetskova I. V.
}

\begin{abstract}
The paper aims to identify the linguistic status of German pejorative lexemes used to describe a person on the basis of lexicographic references. The article examines German lexical units which demonstrate a high level of expressiveness and include the whole range of negative evaluative, pejorative, depreciative meanings. The scientific originality of the research lies in the fact that it develops the principles of choice of nominations with pejorative meaning from the general lexical fund of the language and identifies the peculiarities of their labeling in German and German-Russian lexicographic sources. As a result of the quantitative, stylistic and etymological analysis, 1492 nominations with pejorative semantics have been revealed, the characteristic features of pejoratives have been identified, the pejorative labels and their variants in different dictionaries and references have been characterized.
\end{abstract}

\section{Введение}

Термин «пейорация» является многозначным, так, в широком смысле под пейорацией понимается отрицательная оценочность. В более узком - отрицательная, эмоционально-нагруженная экспрессивная оценочность (Турецкова, 2011, с. 7). Данная дефиниция будет использована нами в настоящей публикации во втором, более конкретизированном значении.

В качестве объекта исследования выступают средства выражения пейоративности в современном немецком языке в аспекте лексикографического представления. Актуальность проблемы манифестации пейоративности обусловлена отсутствием в германистике, более того - в целом в теоретической лингвистике - четко разработанных единых принципов выделения пейоративных слов и словосочетаний из общего пласта лексики того или иного языка. На данный момент нет ни одного словаря негативно-оценочной лексики, а именно пейоративных лексем.

В соответствии с целью исследования становится необходимым решение следующих задач: установить особенности пейоративных номинаций, используя разные словари; определить характер лексикографирования немецких пейоративных имен; сравнить специфику этико-стилистической сниженности словарных помет в разных лексикографических справочниках; рассмотреть представление пейоративных лексем в этимологическом словаре.

Пейоративные номинации будем анализировать с помощью следующих методов: метод сплошной выборки - будем отбирать слова, маркированные пометами; метод стилистического анализа - постараемся 
распределить слова по стилистической окраске в соответствии с их стилистическим описанием; статистический метод - подсчитаем количество пейоративных единиц; сравнительный метод - сравним несколько словарей разных авторов и авторских коллективов.

Однозначному отбору слоя пейоративной лексики мешает отсутствие в словарях ее общепринятой маркированности. Вслед за многими лингвистами будем принимать в качестве критерия пейоративности стилистическую помету abwertend (уничижительный). Но одной пометой невозможно охватить все эмоциональные варианты, из которых и складывается отрицательная эмоционально-оценочная, экспрессивная окраска слов, способная порождать негативную эмоциональную реакцию у реципиента. Поэтому лексикографы применяют целый ряд стилистических указателей пейоративности: abw., pejor., spött., Schimpfwort, herabschätz., iron., verächtl., vulgär, derb (в немецком языке), бран., груб., неодобр., ирон., презр., пренебр., оскорбит., пейор., уничшжит. (в русском языке). Однако одно и то же слово может по-разному трактоваться в разных словарях, сопровождаться разными пометами, а может и вовсе не иметь никакого стилистического комментария. В связи с этим при отборе пейоративной лексики необходимо принимать во внимание такие характеристики, как наличие признака уничижительности в словарном описании, включение слова в разделы «Обман», «Клевета», «Угодничество» в Большом толковом словаре немецкого языка, пейоративно-оценочный характер контекстов, в которых употребляется слово.

Теоретической базой исследования послужили работы следующих языковедов: В. Д. Девкина (1994; 2005), И. И. Кремиха (1987), Н. Б. Савинкиной (1987), А. И. Смирницкого (1998), С. С. Хидекель и Г. Г. Кошель (1981), В. М. Пронькиной (2018), Е. В. Бастинович (2021), С. Бастиан (Bastian, 2013). Эти лингвисты указывают в качестве основного критерия разграничения пейоративных единиц словарные пометы. Однако не все негативнооценочные слова имеют соответствующую лексикографическую маркированность, некоторые вовсе не имеют стилистических помет. Так, например, только 17\% пейоративных существительных сопровождаются соответствующими пометами в словарях немецкого языка. Этот недостаток компенсируется вторым критерием толкованием слова. Показателем пейоративности выступают качественные прилагательные, содержащиеся в словарной дефиниции и обладающие негативно-оценочным значением. Этим же критерием, по всей видимости, руководствовался Герберт Пфайффер (Pfeiffer, 1999) при составлении словаря “Das große Schimpfwörterbuch”. Здесь представлено около 10000 так называемых ругательств с указанием их значения, происхождения, стилистической принадлежности, употребления. Помимо этого, собрано около 2000 прилагательных, употребляющихся в сниженном значении для дополнительного рассмотрения объекта ругательств.

Практическая значимость результатов заключается в возможности их применения при чтении лекций по лексикологии и стилистике немецкого языка, теории и практике перевода, а также при чтении спецкурсов студентам-германистам. Представленный материал может быть использован в лексикографической практике с целью создания словарей пейоративов с соответствующими пометами.

\section{Основная часть}

\section{Особенности маркирования немецких пейоративных номинаций}

В качестве материала исследования используем словарь Герхарда Варига (Wahrig, 2011) (260000 слов и выражений), как достаточно авторитетный источник, представляющий собой словарный запас стандартного немецкого языка. Рассмотрим словарные статьи случайно выбранных букв W, M, U. Полученные результаты представим в Таблице 1.

Таблица 1. Пометы в словаре Г. Варига

\begin{tabular}{|c|c|c|c|}
\hline \multirow{2}{*}{ Пейоративные пометы } & \multicolumn{2}{|c|}{ Количество слов в каждой букве - процент маркированных единиц } \\
\cline { 2 - 4 } & $\mathbf{W}$ & $\mathbf{M}$ & $\mathbf{U}$ \\
& 11635 слов & 3916 слов & 1534 слова \\
\hline abwertend (уничижит.) & $73-0,62 \%$ & $22-0,56 \%$ & $5-0,32 \%$ \\
\hline derb (груб.) & $86-0,73 \%$ & $6-0,15 \%$ & $1-0 \%$ \\
\hline ironisch (ирон.) & $25-0,21 \%$ & $7-0,17 \%$ & $1-0 \%$ \\
\hline verächtlich (презрит.) & $8-0,06 \%$ & $1-0 \%$ & - \\
\hline vulgär (вульгар.) & $2-0 \%$ & - & $1-0 \%$ \\
\hline
\end{tabular}

Толковый словарь Г. Варига включает 10 стилистических помет, 5 из которых указывают на пейоративнооценочную окраску слова. Наиболее частотными по употреблению являются лишь 50\% пейоративных помет, причем самая распространенная помета - “abwertend” (уничижит.). Остальные пометы встречаются в единичных случаях.

Для сравнения специфики стилистических помет в одноязычном и двуязычном словаре возьмем словарный состав этих же букв в словаре В. Дуды, М. Френцеля, М. Глодде (2002) (180000 слов и словосочетаний). Получим данные, немного отличающиеся в количественном и процентном отношении от первых (см. Таблицу 2 ).

Авторы данного словаря используют 11 стилистических характеристик слова. 6 помет имеют пейоративный характер. Кроме того, наблюдается не только количественная разница помет, но и их качественная характеристика. Перечень стилистических помет расширен за счет «бранных слов», «пренебрежительных», «неодобрительных» слов, которые отсутствовали в лексикографических описаниях Г. Варига. Наблюдается и другая тенденция: Г. Вариг включает пометы “vulgär” (вульгар.), “abwertend” (уничижит.), которые 
отсутствуют в словаре В. Дуды, М. Френцеля, М. Глодде. Изменилась и частотность употребления помет. Схожей тенденцией при сравнении этих двух словарей оказалось количественное превосходство пейоративных помет над мелиоративными. Это можно объяснить стремлением авторов словарей отразить словарный состав языка как можно ближе к реальной жизненной картине, не пытаясь как-то ее улучшить и эвфемизировать. Например, нейтральное слово der Alte - старик имеет следующие синонимичные варианты с пейоративным эмоционально-оценочным компонентом: alte Fummel (starkes Schimpfwort) - cmapaя карга, Hutzelmännchen (absch.) - маленький сморщенный старичок, Vettel (grob, Schimpfwort) - cтарая карга, сплетница, Methusalem (leicht abw.) - древний (о старике разг.), Patriarch (abw.) - патриарх (в перенос. знач. о старике), Muтіе (salopp, abw.) мумия (перен. о старом человеке), Muтmelgreis (gering.) - дряхлый старик и др., и их гораздо больше, чем мелиоративных наименований лиц пожилого возраста. Это свидетельствует о негативном отношении к «старости», особенно в профессиональной сфере и в среде молодежи. Негативной оценке подвергаются внешность, рассеянность, нерасторопность, забывчивость и другие характеристики пожилого возраста.

Таблица 2. Пометы в словаре В. Дуды, М. Френцеля, М. Глодде

\begin{tabular}{|c|c|c|c|}
\hline \multirow{2}{*}{ Пейоративные пометы } & \multicolumn{2}{|c|}{ Количество слов в каждой букве - процент маркированных единиц } \\
\cline { 2 - 4 } & $\mathbf{W}$ & $\mathbf{M}$ & $\mathbf{U}$ \\
& 11028 слов & 3184 слова & 1347 слов \\
\hline derb (груб.) & $58-0,52 \%$ & $19-0,6 \%$ & $3-0,22 \%$ \\
\hline spöttisch (насмешл.) & $38-0,34 \%$ & $12-0,37 \%$ & $3-0,22 \%$ \\
\hline geringschätzig (пренебреж.) & $37-0,33 \%$ & $8-0,25 \%$ & - \\
\hline Schimpfwort (бранн.) & $11-0,09 \%$ & $3-0,09 \%$ & $1-0,07 \%$ \\
\hline verächtlich (презрит.) & $9-0,08 \%$ & $1-0,03 \%$ & - \\
\hline mißbilligend (неодобрит.) & $7-0,06 \%$ & - & \\
\hline
\end{tabular}

Литературный язык стремится к норме. Отражая конкретную историческую сущность, норма языка меняется вместе с изменениями в обществе, переходит от старого качества к новому. Чаще всего изменение литературного языка прослеживается в устной речи. Литературная норма более консервативна в области орфографии и более свободна в области произношения, а также изменения слов и словосочетаний. Формальная вариация и синонимика делают литературный язык мощным средством коммуникации, основной нормой языка, его общей формой. Все остальные разновидности и отклонения подчинены этой основной норме языка - основе ее вариации.

Назначение словаря - как можно точнее зафиксировать и описать языковые явления, не навязывая авторской позиции составителя словника. Распределение лексических единиц в словаре по разным регистрам речи и сферам употребления - это постоянная проблема, с которой сталкиваются лексикографы при составлении словаря. В связи с «подвижностью» нормы отсутствуют четкие границы словоупотребления. Лексические единицы зачастую перемещаются из одной сферы употребления в другую, занимают промежуточные стилевые позиции. Однако автору словаря следует в словарных статьях провести четкие стилевые различия между разными примерами употребления слов, иначе лексическая система языка будет отражена необъективно.

При составлении лексикографического справочника самым сложным является отбор ненормативной лексики, не входящей в литературный пласт языка. Именно эта лексика, как правило, отмечается лексикографами специальными пометами. Пассивная часть лексикографических справочников постоянно увеличивается за счет неологизмов, молодежных дуплетов, сленговых выражений, современных терминов.

Помимо проблемы отбора негативно-окрашенной, экспрессивной лексики при анализе словарей возникает другой вопрос: зависит ли количество маркированных единиц от объема словника? Предположим, что количество пейоративных лексем увеличится по мере увеличения словаря либо процент помеченных лексических единиц останется неизменным. Для проверки нашего предположения обратимся к восьмитомному справочнику издательства Дуден (Duden, 1993), в который входит более 780000 ключевых слов, значений и примеров их употребления. В выборе словаря будем руководствоваться в данном случае лишь объемом лексикографического справочника. Несмотря на количественную разницу слов по сравнению с двумя предыдущими источниками, процент маркированных лексем изменился не столь существенно (см. Таблицу 3).

Таблица 3. Пометы в восьмитомном словаре Дуден

\begin{tabular}{|c|c|c|c|}
\hline \multirow{2}{*}{ Пейоративные пометы } & \multicolumn{2}{|c|}{ Количество слов в каждой букве - процент маркированных единиц } \\
\cline { 2 - 4 } & $\mathbf{W}$ & $\mathbf{M}$ & $\mathbf{U}$ \\
& 17471 слово & 7849 слов & 3964 слова \\
\hline abwertend & $649-3,71 \%$ & $256-3,26 \%$ & $46-1,16 \%$ \\
\hline derb & $94-0,53 \%$ & $49-0,62 \%$ & $7-0,17 \%$ \\
\hline ironisch & $77-0,44 \%$ & $41-0,52 \%$ & $6-0,15 \%$ \\
\hline Schimpfwort & $32-0,18 \%$ & $8-0,1 \%$ & $4-0,1 \%$ \\
\hline verächtlich & $8-0,04 \%$ & $3-0,03 \%$ & $3-0,07 \%$ \\
\hline vulgär & $4-0,02 \%$ & $2-0,02 \%$ & $3-0,07 \%$ \\
\hline
\end{tabular}

Анализ вышеприведенных лексикографических источников показал, что количество пейоративных единиц не зависит от объема словника. Несмотря на достаточно ощутимую разницу в количестве словарных 
статей и их маркировке, процент помеченных единиц в каждом из них колеблется от 0 до 3. Не все пейоративные единицы сопровождаются соответствующими пометами. Иногда разговорная окраска - это объективное качество, которое интуитивно распознается носителем языка. Поэтому наличие достаточно расширенной системы пейоративных помет не гарантирует точности описания лексики сниженного регистра.

Английский лингвист Р. Тренч (Trench, 1857) определил правила, которых нужно придерживаться при составлении лексикографического справочника.

1. Лексикографический справочник показывает лексику современного языка в синхронии.

2. Лексикографический справочник обязан отражать все значения слов.

3. Лексикографический справочник должен описать слово в диахронии, т.е. представить по возможности все этапы исторического развития слова.

4. Лексикографический справочник должен подтверждать значение слова контекстным окружением. Следует учесть, что пометы служат для определения сферы применения данного слова и его стилистической соотнесенности.

\section{Манифестация пейоративных номинаций в этимологическом словаре}

Для более полной картины репрезентации пейоративной лексики в лексикографических справочниках рассмотрим пейоративные номинации лица на материале этимологического словаря Дуден (Duden, 2007). В рамках данной работы представляется возможным проиллюстрировать лишь некоторые словарные статьи из полученного списка примеров.

Заимствованные слова:

Alkoholiker - arab. Alkohol in der Bedeutung “Weingeist” (араб. заимств. «пьяница, алкоголик»);

Bandit - Der Ausdruck für “Strassenräuber, Gauner” wurde Anfang des 16. Jh.s aus it. bandito entlehnt (итал. заимствование со знач. «плут, жулик, подонок»).

Исконно-немецкие слова:

Hochstapler - Das seit dem 18. Jh. bezeugte Wort stammt aus der Gaunersprache und bezeichnete zunächst vornehm auftretenden Bettler («шарлатан, аферист, мошенник», в XVIII в. служило названием для благородных нищих);

Schwindler - bedeutete im 17. Jh. "Schwärmer, Fantast", zu Ende des 18. Jh.s aber geriet unter den Einfluss von engl. Swindler "Betrüger” (в XVII в. означало «мечтатель», в XVIII в. - «обманщик, шарлатан»);

Frauenzimmer - urspr. “Aufenthaltsraum der Frauen”, heute “Frau” (раньше «женская комната отдыха», сейчас пренебр. «баба»);

Memme - Das seit dem 16. Jh. bezeugte Schimpfwort für einen Feigling geht zurück auf mhd. memme, mamme "Mutterbrust, Mutter”, das ein Lallwort der Kindersprache ist («трус, баба», в ср.-в.-нем. - «родная мать», «мамочка»);

Hasenherz - altgerm. Auf die Eigenschaft des Hasen, seine Furchtsamkeit bezieht sich die Zusammensetzung (в древнегерм. «трус, баба (о мужчине)», трусливость зайца переносится на обозначение трусливого человека);

Faulpelz - Es beruht auf einem idg. Verbalstamm pŭ, dem wohl ein lautmalendes pu “pfui!” zugrunde liegt (произошло от индогерм. слова со знач. «лентяй»);

Tagedieb - eigentlich “j-d, der dem lieben Gott den Tag stiehlt”, Ende des 17. Jh.s (в значении «лентяй, лоботряс, лодырь», в XVII в. обозначало человека, «который крадет день даже у Бога»);

Witzbold - seit dem Anfang des 19. Jh.s “Spaßmacher, Spötter” (с XIX в. означает «балагур, шут, клоун»);

Schafskopf - Der Name eines der ältesten deutschen volkstümlichen Kartenspiele geht zurück auf die dem Kopf eines Schafs ähnliche Figur, die durch die Strichnotierung der gewonnenen und verlorenen Spiele entsteht («болван, балда» исходит от названия одной из немецких карточных игр, в результате штрихового обозначения выигранных и проигранных туров в которой появляется изображение, похожее на голову животного).

Нами было установлено, что исконно-немецких пейоративов гораздо больше заимствованных слов с пейоративной окраской. Данное превосходство не случайно, так как ПЕ отражают особенности развития языка, общества и общественных отношений, и каждый язык имеет свою самобытную систему пейоративной лексики.

\section{Заключение}

Опираясь на лексикографические справочники разных авторов, мы собрали словарь пейоративной лексики немецкого языка, содержащий пейоративные наименования лиц, русская версия которых зафиксирована в различных немецко-русских словарях. Данный словарь включает 1492 единицы, несущие уничижительную оценку в их семантической структуре. Были выявлены их русскоязычные соответствия, которые оказались менее многочисленны, чем немецкие наименования. В целом в русском языке обнаружено 657 пейоративных лексем. Остальные русские эквиваленты либо вообще не являются пейоративами, либо представляют собой повтор уже имеющихся пейоративных единиц.

Анализ стилистических маркеров разных словарных источников позволяет сделать нам следующие выводы. В словаре Г. Варига в качестве маркеров пейоративной оценки выступают: 1) abwertend, 2) derb, 3) ironisch, 4) verächtlich, 5) vulgär. В Большом словаре ругательств Г. Пфайффера представлена наиболее разноплановая система маркировки пейоративных номинаций. Составитель словаря приводит наряду с непосредственно пейоративными пометами еще и пометы, конкретизирующие и детализирующие пейоративную оценку (“geliebtes Schimpfwort” - «излюбленное ругательство», “weitverbreitetes Schimpfwort” - «широко распространенное ругательство», “Berufsspott” - «профессиональная насмешка», “selten verächtlich” - «редко презрительно», “milde Schelte” - «мягкое порицание», “leicht spöttisch” - «слегка насмешливо» и др.). Автор 
данного словаря фиксирует пейоративную оценку очень разнопланово. Сравнительный анализ подтверждает ранее выдвинутую нами гипотезу о детальности пейоративов в немецком языке. Некоторые пометы могут дополняться другими пометами, могут заменять их или встречаться в сочетании. Многие лексемы меняют градус негативной оценочности. Например, слово Brausekopf в немецком языке имеет помету (Schimpfwort) и является пейоративом, в переводе на русский язык означает вспыльчивый человек (пейоративная окраска отсутствует). И противоположный случай: слово головорез, душегуб в русском языке маркируется пометами (груб.), [прост., презр.], в немецком - Halsabschneider зафиксировано как (umg.). Вышесказанное свидетельствует о том, что, опираясь только на словарные пометы, сложно определить единые критерии отбора пейоративной лексики. Разный объем лексикографических справочников, неоднородность словарных дефиниций, разное применение стилистических помет, и завершает список «сложностей» субъективное отношение автора словаря к лексическому материалу, включенному в словник. Стилистическая помета выступает в качестве маркера отнесения слова к разряду пейоративной лексики, лингвистический статус которой определяется с учетом не только словарных помет, комментариев к пометам, но и всей словарной дефиниции.

К сожалению, ни один из выбранных нами лексикографических справочников и даже сравнительный анализ нескольких словарей не дают нам полного представления о нормативности лексики того или иного языка и не позволяют решить проблему отбора пейоративной лексики из всего лексического состава языка. Поэтому в качестве перспективы дальнейшего исследования немецких негативно-оценочных номинаций нам видится целесообразным обратиться к контексту, а именно использованию их в электронных корпусах текстов.

\section{Источники | References}

1. Бастинович Е. В. Пейоративы в системе культуры, на примере отрицательных номинаций лиц мужского пола в немецком и русском языках // Modern Humanities Success. Успехи гуманитарных наук. 2021. № 2.

2. Девкин В. Д. Немецкая лексикография: учеб. пособие для вузов. М.: Высшая школа, 2005.

3. Девкин В. Д. Немецко-русский словарь разговорной лексики. М.: Русский язык, 1994.

4. Дуда В., Френцель М., Глодде М. Большой немецко-русский словарь: в 2-х т. М.: АСТ; Астрель, 2002. T. 2. L - Z.

5. Кремих И. И. Пейоративы-переосмысления в лексике современного немецкого языка: автореф. дисс. ... к. филол. н. М., 1987.

6. Пронькина В. М. Особенности перевода пейоративной лексики с английского языка на русский // Научное обозрение. 2018. № 4.

7. Савинкина Н. Б. Пейоративное словообразование в современном немецком языке (на материале имени существительного): автореф. дисс. ... к. филол. н. М., 1987.

8. Смирницкий А. И. Лексикология английского языка. М.: Омен, 1998.

9. Турецкова И. В. Языковые средства манифестации пейоратива в словаре и тексте (на материале немецких пейоративных имен, характеризующих человека): автореф. дисс. ... к. филол. н. Самара, 2011.

10. Хидекель С. С., Кошель Г. Г. Оценочный компонент лексического значения слова // Иностранные языки в школе. 1981. № 4.

11. Bastian S. Fluchen und Schimpfen im Comic - Von Kapitän Haddock zu den BanlieuZards // Alles hängt mit allem zusammen. Translatologische Interdependenzen. Festschrift für Peter A. Schmitt / hrsg. von A.-K. Ende, S. Herold, A. Weilandt. Berlin: Frank \& Timme, 2013.

12. Duden. Das Herkunftswörterbuch. Etymologie der deutschen Sprache. Mannheim: Dudenverlag, 2007.

13. Duden. Das große Wörterbuch der deutschen Sprache: in 8 Bdn. / hrsg. von G. Drosdowski. Mannheim - Leipzig Wien - Zürich: Dudenverlag, 1993. Bd. 5. Bd. 7. Bd. 8.

14. Pfeiffer H. Das große Schimpfwörterbuch. München: Heyne, 1999.

15. Trench R. C. On Some Deficiencies in Our English Dictionaries // Transaction of the Philological Society. 1857. Vol. 4. Iss. 2.

16. Wahrig G. Deutsches Wörterbuch. 9. Auflage. Guitersloh - München: Brockhaus, 2011.

\section{Информация об авторах | Author information}

RU Николаева Наиля Тагировна ${ }^{1}$, к. пед. н., доц.

Турецкова Ирина Валерьевна ${ }^{2}$, к. филол. н.

1,2 Оренбургский государственный педагогический университет

EN Nikolaeva Nailya Tagirovna ${ }^{1}, \mathrm{PhD}$

Turetskova Irina Valeryevna ${ }^{2}, \mathrm{PhD}$

1,2 Orenburg State Pedagogical University

${ }^{1}$ niknt76@mail.ru, 2 swabra@rambler.ru

\section{Информация о статье | About this article}

Дата поступления рукописи (received): 30.12.2021; опубликовано (published): 28.02.2022.

Ключевые слова (keywords): пейоративы; стилистические пометы; литературная норма; ядерная и пассивная лексика; дефиниция; pejoratives; stylistic labels; literary norm; kernel and passive vocabulary; definition. 